\title{
Identification and Classification of Complex Agricultural Croplands Using Multi-Temporal ALOS-2/PALSAR-2 Data: A Case Study in Central Java, Indonesia
}

\author{
Prima Rizky Mirelva ${ }^{1} \&$ Ryota Nagasawa $^{2}$ \\ ${ }^{1}$ The United Graduate School of Agricultural Sciences, Tottori University, Tottori, Japan \\ ${ }^{2}$ Faculty of Agriculture, Tottori University, Tottori, Japan \\ Correspondence: Prima Rizky Mirelva, The United Graduate School of Agricultural Sciences, Tottori University, \\ 4-101 Koyama Minami, Tottori 680-8550, Japan. E-mail: prima.rizky.m@gmail.com
}

Received: November 6, 2017

Accepted: December 5, $2017 \quad$ Online Published: January 15, 2018

doi:10.5539/jas.v10n2p58

URL: https://doi.org/10.5539/jas.v10n2p58

\begin{abstract}
The agriculture sector makes a significant contribution to the Indonesian economy and has become one of the sources of national income. Therefore, precise agricultural mapping is very important to national and regional administrations. Satellite remote sensing provides the most effective tool for identifying a wide expanse of agriculture croplands. However, cloud coverage in tropical regions limits the use of optical remote sensing. SAR is an active remote sensing technique, which offers completely cloud-free observation data. The multi-temporal ALOS-2/PALSAR-2 data were used in this study, complemented by optical multi-temporal remote sensing data, that is, Landsat 8 OLI for classifying complex agricultural croplands. The study area, located in the Klaten Regency, Central Java Province, with $112 \mathrm{~km}^{2}$ coverage, was selected because of its dynamic cropping pattern and complex agricultural land use types. In this study, the RGB composite of HH, HV and HV-HH, derived from ALOS-2/PALSAR-2 polarizations, was found to be effective at separating two types of paddy field cropping pattern: all-year paddy (paddy-I) and paddy upland fields (paddy-II). The multi-temporal Landsat 8 data were also found to be useful for observing the cropping pattern. Moreover, the classification accuracy, which was as high as $85.02 \%$ in terms of overall accuracy, with a kappa coefficient of 0.824 , from multi-temporal ALOS-2/PALSAR-2 data, was obtained. These results show that multi-temporal ALOS-2/PALSAR-2 data are capable of discriminating between two different paddy field cropping types, as well as beneficial for discriminating between the cropping stage and cropping pattern information for several other land uses.
\end{abstract}

Keywords: agricultural land use, multi-temporal SAR, ALOS-2/PALSAR-2, Central Java

\section{Introduction}

Indonesia, like many Southeast Asian countries, depends on agriculture as one of national income sources, as well as for economic growth and fulfilling the country's consumption needs. According to Statistics Indonesia's 2014 report, the agricultural sector (including forestry and fishery) contributed 13.38\% of Indonesia's gross domestic product. Moreover, a substantial 32\% of Indonesians in rural areas work in the agricultural sector. The agriculture croplands are mainly located on Java Island, where smallholding farmers cultivate agricultural cropland near volcanos due to the fertile soil available.

The small-scale cultivated fields on Java typically follow the terrain contour. In general, horticultural crops are planted in upland areas, which range from flat to hilly, while paddy fields are mostly found in flat areas at lower altitudes. Agricultural parcels in Indonesia are small, around 0.3 ha per household (Agus \& Manikmas, 2003), with many farmers often being sharecroppers who do not own their fields. Farmers have limited access to technology and are highly dependent on the seasonal weather for maintaining their crops. The intercropping method is usually applied to increase farmers' incomes. As such, it is uncommon to find distinctive cropping patterns and types on adjacent agricultural croplands. These conditions increase the complexity of monitoring complex agricultural cropland on Java Island.

The Indonesian government monitors agricultural areas on Java Island by using direct field surveys and the remote sensing technology. There are two kinds of remote sensing technology: optical and radar-based remote sensing. The optical remote sensing satellite captures the spectral value of the earth's surface via sunlight 
reflectance and provides high temporal data. Atmospheric conditions, such as clouds, limit the usage of optical data, while the radar-based remote sensing capability is unaffected. The satellite sensor for radar-based remote sensing, also known as synthetic aperture radar (SAR), transmits specific wavelengths and receives the scatter from the earth's surface. Common wavelengths for SAR sensors are the X-band $(2.5-4 \mathrm{~cm})$, C-band $(4-8 \mathrm{~cm})$ and L-band $(15-30 \mathrm{~cm})$. SAR sensors using longer wavelengths penetrate deeper vegetation cover than those using shorter ones, as well as provide temporal data day and night and overcome the limitations caused by cloud cover, which often occurs in tropical areas.

In recent years, many researchers have monitored agriculture using SAR data because of their sensitivity to the moist conditions and surface roughness of the areas monitored. Paddy fields are frequently monitored by a SAR because the inundation stage of the early planting season is useful as a key factor, which allows the SAR to distinguish between paddy fields from other crops and land uses. Some studies have used SAR for paddy field identification and mapping (Y. Zhang, Wang, \& Q. Zhang, 2011; Nelson et al., 2014), paddy field monitoring (Torbick et al., 2017), and paddy yield estimation (Inoue, Sakaiya, \& Wang, 2014). Other studies have shown SAR to be highly effective in classifying whether a paddy is abandoned or not, identifying rubber and oil palm agricultural land (Yusoff et al., 2016), classifying crops (Tian et al., 2010), and separating tall vegetation from short vegetation (Mishra, Singh, \& Yamaguchi, 2011).

The Advanced Land Observing Satellite 2 (ALOS-2) was launched on May 24, 2014. Mounted on the ALOS-2 is the second-generation Phased Array Type L-band Synthetic Aperture Radar (PALSAR-2) sensor (Kankaku, Suzuki, \& Osawa, 2013). The number of agricultural monitoring applications using SAR in Indonesia is still limited, especially when involving ALOS-2/PALSAR-2. This study aimed to analyze the ability and emphasize the advantages of multi-temporal ALOS-2/PALSAR-2 data for identifying complex agricultural croplands and classifying other land uses near agricultural cropland. Furthermore, this study was carried out to investigate the useful backscatter characteristics of temporal PALSAR-2 data for separating out the paddy field planting stages.

\section{Materials and Methods}

\subsection{Study Area}

The study area covered $112 \mathrm{~km}^{2}$ of the Klaten Regency in Indonesia's Central Java Province, within the following geographic coordinates: $7^{\circ} 37^{\prime} 10.7^{\prime \prime}-7^{\circ} 42^{\prime} 56.8^{\prime \prime}$ south latitude and $110^{\circ} 29^{\prime} 31.89^{\prime \prime}-110^{\circ} 35^{\prime} 17.02^{\prime \prime}$ east longitude (Figure 1). It is located on the southeastern slopes of Java's most active volcano, Mount Merapi, with elevations of $200-600 \mathrm{~m}$.
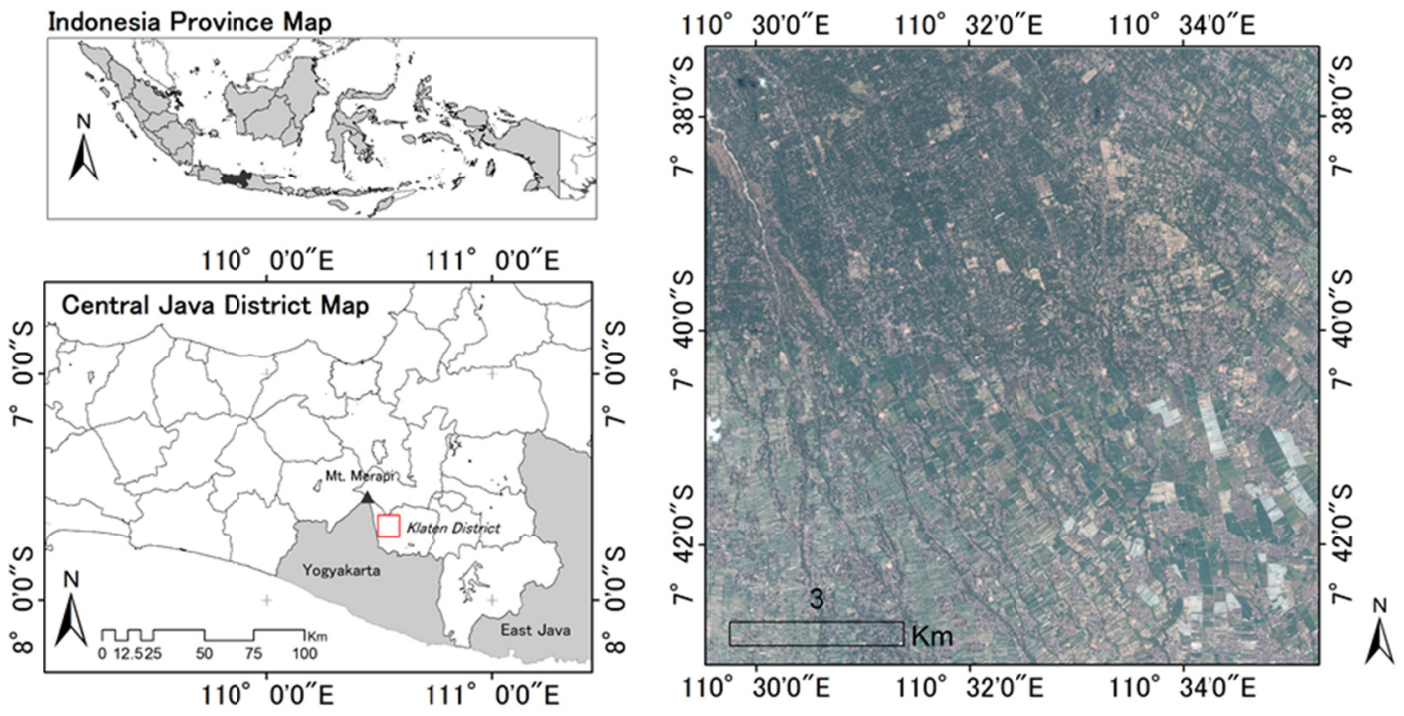

Figure 1. Location of study area and coverage of Pleiades

Despite frequent volcanic eruptions, people continue to live and work in this hazardous area because of the strong relationship between the Javanese people and the mountain (Lavigne et al., 2008). They view Mount Merapi as a sacred living thing, which provides abundant natural resources (Nofrita \& Krol, 2014; Mei et al., 
2013), given that the fertile soil resulting from the eruptions is highly beneficial to their agricultural activities. Therefore, many households depend on the agricultural sector and work as farmers or sharecroppers. Land use in the study area generally consists of woodland, settlements, paddy fields, upland fields, tobacco fields and mixed garden crops. The distribution of land covers differs in the northern and southern parts according to topographic conditions. The hilly northern part has woodlands, upland fields and mixed garden crops, while paddy fields, tobacco fields and some upland fields are located in the flat or gently sloping areas of the southern part. The settlements are spread across both southern and northern parts of the study area.

\subsection{Remotely Sensed Data and Preprocessing}

ALOS-2/PALSAR-2 is provided by the Japan Aerospace Exploration Agency (JAXA) and delivers higher resolution SAR images than its predecessor, ALOS/PALSAR (Rosenqvist et al., 2014). This study used multi-temporal dual polarization and full polarization data in the highly sensitive mode with a $6.85 \mathrm{~m}$ resolution as the primary data. The dual polarization of PALSAR-2 consisted of $\mathrm{HH}$ and $\mathrm{HV}$ polarizations and the full polarization consisted of $\mathrm{HH}, \mathrm{HV}, \mathrm{VH}$ and $\mathrm{VV}$ polarizations. The first letter of polarization indicates the transmission direction, while the second letter indicates the received direction. $\mathrm{H}$ stands for horizontal and $\mathrm{V}$ for vertical direction. The complementary data are from Pleiades and the Landsat 8 Operational Land Imager (OLI), which hereafter will be referred to as Landsat 8 . Pleiades is an ortho-rectified multi-spectral imagery satellite with a $0.5 \mathrm{~m}$ spatial resolution, while Landsat 8 is a multispectral image satellite with a $30 \mathrm{~m}$ spatial resolution. These complementary data were used for a preliminary study of the land use and cropping patterns in the study area. In addition, Pleiades was used for the base image in the georeference process. Table 1 describes the detailed acquisition of primary and complementary data used in this study. The date acquisition description in the yyyy.mm.dd format will be used hereafter. The field survey was performed twice, on March 25, 2017, and August 24-25, 2017, in order to validate the land use and cropping patterns in the study area.

Table 1. Acquisition description of primary and complementary data used in this study

\begin{tabular}{lllll}
\hline Primary data & $\begin{array}{l}\text { Acquisition date in } \\
\text { yyyy.mm.dd }\end{array}$ & Complementary data & \multicolumn{2}{l}{$\begin{array}{l}\text { Acquisition date in } \\
\text { yyyy.mm.dd }\end{array}$} \\
\hline ALOS-2/PALSAR-2: Level 1.1 & & Pleiades Image & 2015.08 .26 & \\
- Dual polarization & 2015.01 .30 & Landsat 8 Images (12 images) & 2015.01 .05 & 2015.07 .16 \\
(HH \& HV polarizations) & 2015.07 .03 & & 2015.02 .22 & 2015.08 .01 \\
& 2015.09 .11 & & 2015.03 .26 & 2015.09 .02 \\
& 2015.05 .17 & & 2015.05 .13 & 2015.09 .18 \\
- Full polarization & & & 2015.05 .29 & 2015.10 .04 \\
(HH, HV, VH, and VV polarizations) & & & 2015.06 .14 & 2015.10 .20 \\
\hline
\end{tabular}

\subsubsection{ALOS-2/PALSAR-2 Preprocessing}

Sentinels Application Platform (SNAP) software from the European Space Agency (ESA) provides the tools for processing Sentinel-1 satellite data, as well as other satellite data, such as from PALSAR-2. The preprocessing steps are (i) calibration, (ii) multi-look with a 1:2 ratio for azimuth and range (JAXA, 2014), (iii) co-registration, (iv) speckle filtering for reducing the noise in SAR data, (v) geocoded processing and (vi) backscatter coefficient calculation.

All PALSAR-2 data were stacked and co-registered together by using the Shuttle Radar Topographic Mission digital elevation model (SRTM DEM). The single product speckle filter was applied based on the Lee speckle filtering method with a window size of $5 \times 5$. The PALSAR-2 data were geocoded to the Universal Transverse Mercator (UTM) projection 49S with World Geodetic System 1984 (WGS84) datum. The topographic effect was corrected using the SRTM DEM. The results of the geocoded images formed a subset based on study area coverage and were confirmed to have a perfect fit with the Pleiades image. The backscatter coefficient in decibel units (dB) was then calculated using this formula (JAXA, 2017) where the Cf and A are calibration factors with a value of -83 and $32 \mathrm{~dB}$, respectively.

$$
\text { Backscatter coefficient }=10 \times \log _{10}(\text { polarization })+C f-A
$$

\subsubsection{Landsat-8 Preprocessing}

Landsat 8 data were processed using ERDAS Imagine 9.2 software. The preprocessing steps were (i) conversion from a digital number to a reflectance value with sun angle correction (USGS, 2014), (ii) the study area subset 
and (iii) the cloud removal process. The Iterative Self-Organizing Data Analysis Technique (ISODATA) method (Helmer \& Ruefenacht, 2005) was used for removing cloud cover from the study area. Then, cloud-free Landsat 8 data were examined to observe the growing stage of the agricultural cropland between the acquisition dates of the PALSAR-2 data.

\subsection{Sample Point Collection and Classification Method}

Sample points, consisting of training and accuracy assessment points, were randomly selected by using a combination of visual interpretations from PALSAR-2, Pleiades and Landsat 8 data. PALSAR-2 data are sensitive to water. Therefore, the red-green-blue (RGB) channel composite was set with a backscatter coefficient of $\mathrm{HH}, \mathrm{HV}$ and $\mathrm{HV}-\mathrm{HH}$ polarizations and used to separate the paddy fields in the early growing stage (inundated phase) from those in the late stage (generative phase). A previous study (Cazals et al., 2016) showed that the RGB composite of VV, VH and VH-VV Sentinel-1 data was useful for identifying the moisture condition of wetland areas. In this study, a similar approach was implemented using $\mathrm{HH}, \mathrm{HV}$ and $\mathrm{HV}-\mathrm{HH}$ polarizations instead of VV, VH and VH-VV, for identifying paddy fields. Other land uses, such as tobacco fields, settlements, woodland upland fields and mixed garden crops, were identified and selected based on visual interpretations in the Pleiades and Landsat 8 data. After collecting the sample points for all land use, the points were divided into training points $(70 \%)$ and accuracy assessment points $(30 \%)$. The supervised classification method, known as maximum likelihood classification, was used for the classification process. The accuracy assessment of remote sensing classification results can be estimated by calculating the error matrix, which consists of producer accuracy and user accuracy for each class, overall accuracy and the kappa coefficient as total accuracy (Congalton, 1991). Producer accuracy is related to the proportion of correctly classified reference samples, while user accuracy is related to sample or training points that are correctly classified (Mas et al., 2014). Overall accuracy and the kappa coefficient are related to classification accuracy in general.

\section{Results and Discussions}

\subsection{Remotely Sensed Data Processing Results}

\subsubsection{ALOS-2/PALSAR-2 Backscatter Coefficient}

Figure 2 shows the backscatter coefficient of PALSAR-2 polarizations. The brightness of the backscatter coefficient could be used to identify the surface roughness condition and/or water content in the study area. In general, HV polarization has a lower average value than $\mathrm{HH}$ polarization, which affects the image brightness intensity color. The bright color in $\mathrm{HH}$ polarization indicates a rougher surface condition and less water content. It also has a higher backscatter coefficient than the darker color. Bareland and concrete buildings will have a stronger backscatter coefficient than water body areas, which give a weak or almost no backscatter. Therefore, the water body or high water content area appeared darker.

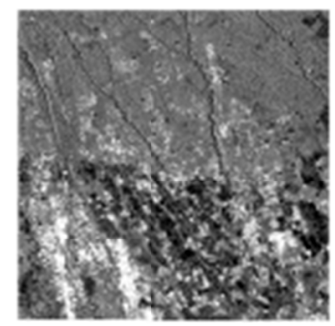

2015.01.30_HH

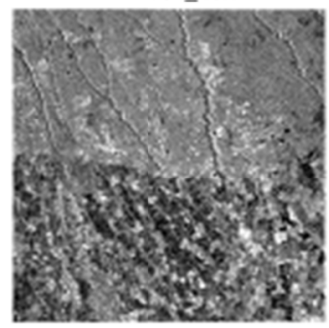

2015.05.17_VV

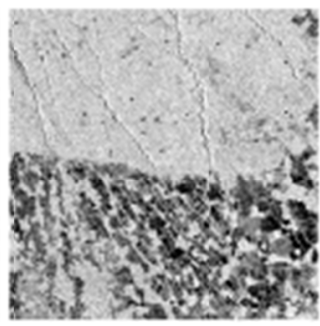

2015,01.30 HV

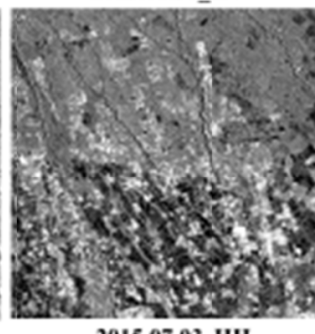

2015.07.03_HH

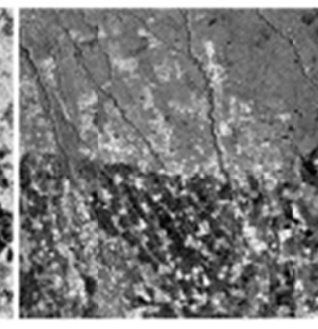

2015.05.17_HH

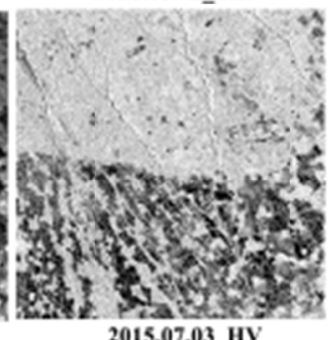

2015.07.03_HV

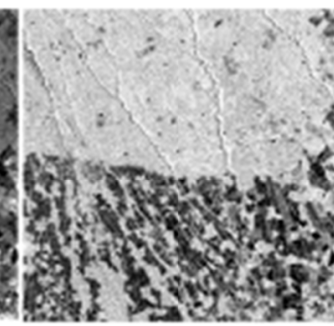

2015.05.17_HV

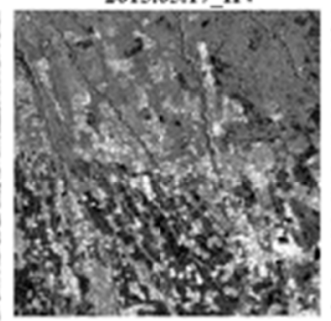

2015,09.11 Нн

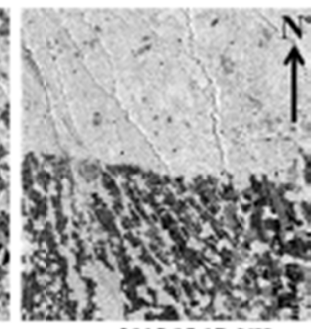

2015.05.17_VH

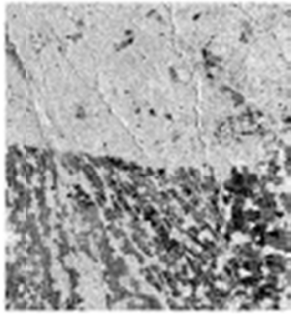

2015.09.11_HV

Figure 2. Backscatter coefficient of PALSAR-2 polarizations 
In Figure 2, there were temporal changes in the southern part as indicated by the color variation in $\mathrm{HH}$ polarizations of the PALSAR-2 backscatter coefficient. The cropping activities in the paddy fields, tobacco fields and upland fields in the southern part of the study area affect the backscatter coefficient value. Paddy fields require large amounts of water in the early planting stage. Therefore, the paddy fields scatter different backscatter coefficient strengths between the inundated and harvested periods. The HH polarization for January 30,2015 , in the southwestern part appeared very bright compared to other acquisition dates because the surface was rough and lacked water content or was very dry. This is an indication that the fields were being prepared for other agricultural activities or just harvested. Thus, the backscatter coefficient is very strong. The tobacco fields and upland fields have varied backscatter coefficients during the growing stages. The northern part of the study area was mostly covered by woodland and mixed garden crops, which were surrounded by perennial trees and indicated less temporal change compared to the upland fields, thereby affecting the brightness of the backscatter coefficient in terms of appearing consistent.

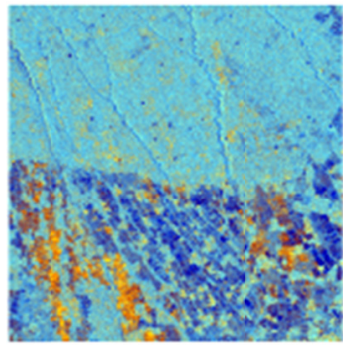

2015.01.30

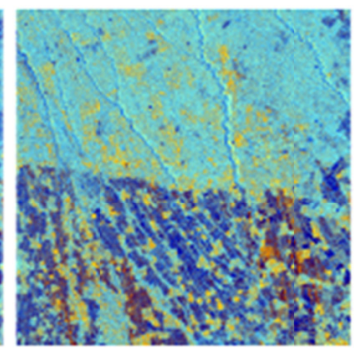

2015.05.17

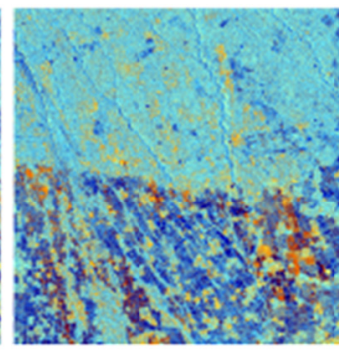

2015.07.03

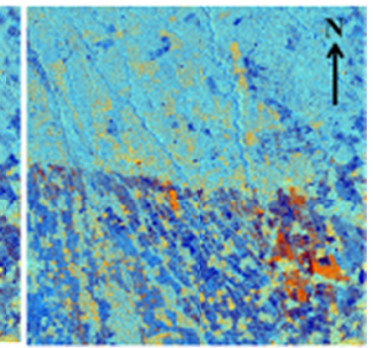

2015.09.11

Figure 3. RGB composite of HH, HV, VH-VV of ALOS-2/PALSAR-2

Based on the field survey, it was found that paddy field irrigations in this study area are not equally distributed. These irrigation conditions influence the paddy fields' cropping patterns in the southwestern and southeastern parts of the study area. Therefore, the paddy fields in this study are divided into two classes: paddy-I and paddy-II. The paddy-I class was made up of paddy fields with adequate irrigation, which were cultivated either three times a year or five times in two years. The paddy-II class was rain-fed and cultivated as paddy fields in the wet season and changed to upland fields in the dry season. In this study, the RGB composite of HH, HV and HV-HH polarizations was used for the separation of these paddy fields' cropping patterns. Figure 3 shows the RGB composite of HH, HV, HV-HH polarizations for each PALSAR-2 data. The low backscatter coefficient areas, which appeared as dark blue, were interpreted as being inundated or in an early vegetative stage. These areas are categorized as paddy-I. Meanwhile, the paddy fields in a late growing stage, or those being prepared for a change of crop, showed more roughness and a higher backscatter coefficient. They appeared as bright orange on the RGB composite and categorized as paddy-II.

\subsubsection{Landsat 8 Preprocessing Results}

The cloud-free Landsat 8 data in a true-color composite (reflectance bands of 4, 3 and 2) are shown in Figure 4. The temporal changes in cropping patterns could be visually identified. For example, the tobacco fields appeared as a bright white area on the Landsat 8 data for the period from March 26 to September 2, 2015, because of the shade nets used for pest prevention. The tobacco plants in this area took about six months from first planting to harvest. After harvesting, several tobacco shade nets were removed as can be seen in the Pleiades data (Figure 1). 


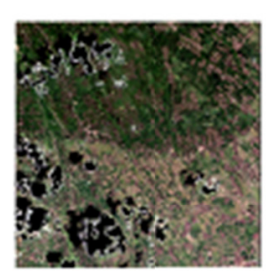

2015.01.05

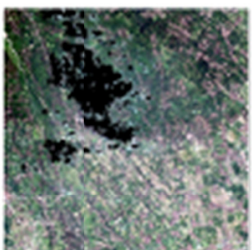

2015.02.22

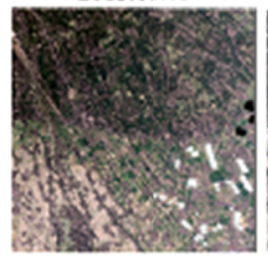

2015.07.16

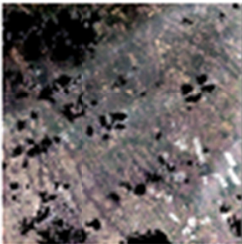

2015.08.01

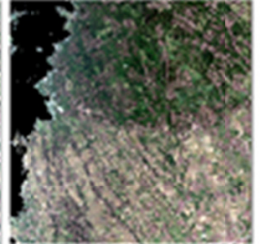

2015.03.26

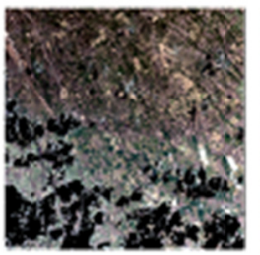

2015.09.02

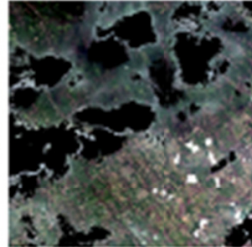

2015.05.13

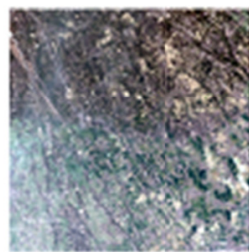

2015.09.18

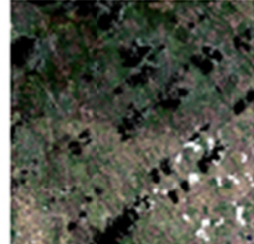

2015.05.29

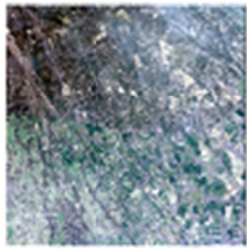

2015.10.04

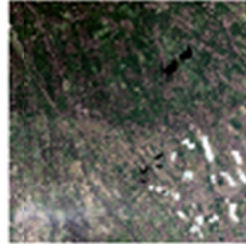

2015.06.14

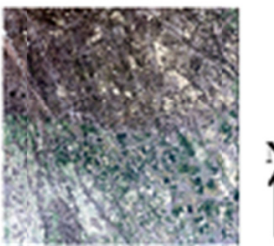

2015.10.20

Figure 4. The cloud-free Landsat 8 data in true color composite (reflectance bands of 4,3,2)

Besides the tobacco fields, the other cropland cropping activities could be identified as well. In the 2015.03.26 image (Figure 4), the southern part was in a dry condition but the vegetation coverage was identified in images for previous (2015.02.22) and later months (2015.05.13 and 2015.06.14). Therefore, other land use classes, except paddy fields, were selected by using visual interpretations of Pleiades and Landsat 8 data with the following descriptions: (i) woodland comprising several trees or non-agricultural tall vegetation, (ii) a settlement comprising housing and nearby home gardens, (iii) upland fields with an open field for growing cassava, maize and horticultural crops, and (iv) an area where mixed garden crops are cultivated, which has similar characteristics to upland fields, but is located near perennial trees or non-agricultural tall vegetation.

\subsection{Training Points Analysis and Classification Result}

In total, there were seven land use classes, namely: paddy-I, paddy-II, woodland, settlements, upland fields, tobacco fields and mixed garden crops. Table 2 shows the training points and accuracy assessment points collected from the analysis of the PALSAR-2 backscatter coefficient and the visual interpretation of Landsat 8 and Pleiades data. The temporal combination column in Table 2 was obtained and randomly selected based on combined paddy-I and paddy-II sample point classes from each acquisition date. These sample points were especially applied with regard to the combination of multi-temporal classification process. The other classes were assumed to have minimum land use change; therefore, the temporal classification process will be used the same set of sample points. The combination and polarization band compositions for the classification process are described in the Table 3. 
Table 2. Training points and accuracy assessment points

\begin{tabular}{lllll}
\hline \multirow{2}{*}{ Class Name } & \multicolumn{3}{c}{ Temporal combination } \\
\cline { 2 - 5 } & TP & AAP & TP & AAP \\
\hline Paddy-I & 74 & 33 & & \\
$2015.01 .30(0130)$ & 70 & 30 & 119 & 50 \\
$2015.05 .17(0517)$ & 71 & 31 & & \\
$2015.07 .03(0703)$ & 56 & 24 & & \\
$2015.09 .11(0911)$ & 70 & 30 & & \\
\hdashline Paddy-II & 73 & 30 & 117 & \\
$2015.01 .30(0130)$ & 56 & 24 & & 33 \\
$2015.05 .17(0517)$ & 35 & 15 & & \\
$2015.07 .03(0703)$ & 78 & 33 & 78 & 38 \\
$2015.09 .11(0911)$ & 55 & 23 & 55 & 36 \\
Upland fields & 90 & 38 & 90 & 37 \\
Tobacco Fields & 85 & 36 & 85 & \\
Woodland & 89 & 37 & 89 & \\
Settlement & 59 & & & \\
Mixed garden crops & & & & \\
\hline
\end{tabular}

Note. TP means training points, AAP means accuracy assessment points.

Table 3. Polarization composition for classification process

\begin{tabular}{|c|c|c|}
\hline Combination name & Polarization composition description & Number of bands \\
\hline 0130_A & $2015.01 .30(\mathrm{HH}, \mathrm{HV})$ & 2 \\
\hline $0130 \mathrm{~B}$ & 2015.01.30 (HH, HV, HV-HH) & 3 \\
\hline 0517_A & 2015.05.17 (HH, HV) & 2 \\
\hline 0517_B & 2015.05.17 (HH, HV, HV-HH) & 3 \\
\hline 0517_C & 2015.05.17 (HH, HV, VH, VV) & 4 \\
\hline 0517_D & 2015.05.17 (HH, HV, VH, VV, HV-HH) & 5 \\
\hline 0703_A & 2015.07.03 (HH, HV) & 2 \\
\hline 0703_B & 2015.07.03 (HH, HV, HV-HH) & 3 \\
\hline 0911_A & 2015.09.11 (HH, HV) & 2 \\
\hline 0911_B & 2015.09.11 (HH, HV, HV-HH) & 3 \\
\hline \multirow[t]{4}{*}{ Temp_comb_1 } & $2015.01 .30(\mathrm{HH}, \mathrm{HV})$ & 8 \\
\hline & 2015.05.17 (HH, HV) & \\
\hline & 2015.07.03 (HH, HV) & \\
\hline & 2015.09.11 (HH, HV) & \\
\hline \multirow[t]{4}{*}{ Temp_comb_2 } & 2015.01.30 (HH, HV, HV-HH) & 12 \\
\hline & 2015.05.17 (HH, HV, HV-HH) & \\
\hline & 2015.07.03 (HH, HV, HV-HH) & \\
\hline & 2015.09.11 (HH, HV, HV-HH) & \\
\hline \multirow[t]{4}{*}{ Temp_comb_3 } & $2015.01 .30(\mathrm{HH}, \mathrm{HV})$ & 10 \\
\hline & 2015.05.17 (HH, HV,VH, VV) & \\
\hline & 2015.07 .03 (HH, HV) & \\
\hline & 2015.09.11 (HH, HV) & \\
\hline \multirow[t]{4}{*}{ Temp_comb_4 } & 2015.01.30 (HH, HV, HV-HH) & 14 \\
\hline & 2015.05.17 (HH, HV,VH, VV, HV-HH) & \\
\hline & 2015.07.03 (HH, HV, HV-HH) & \\
\hline & 2015.09.11 (HH, HV, HV-HH) & \\
\hline
\end{tabular}




\subsubsection{ALOS-2/PALSAR-2 Backscatter Coefficient Characteristics}

Figure 5 shows the averages of the training points of land use classes based on the backscatter coefficient from $\mathrm{HH}$ and HV polarizations from each PALSAR-2 data. Figures 5(a) and 5(b) shows the averages of training points for woodland, settlements, upland fields, tobacco fields and mixed garden crops. The HH and HV polarizations of the paddy-I and paddy-II classes from each acquisition date were shown in Figures 5(c) and 5(d) respectively. In Figure 5(a), the settlement class showed the highest HH polarization backscatter coefficient around $-5 \mathrm{~dB}$ to -3 dB. It can be seen in Figure 5(b) that the HV polarization backscatter coefficient of settlement and woodland classes were almost identical and higher than the other classes. The HV polarization value for these classes was around $-14 \mathrm{~dB}$ to $-12 \mathrm{~dB}$. The dense vegetation and the home gardens close to the settlement areas influenced the HV polarization behavior. The HV polarization for settlement appeared similar to the woodland area. The mixed garden crops also have higher HV polarization backscatter coefficient than upland fields and tobacco fields. Thus, the HV polarization was found to be more sensitive to buildings and tall or dense vegetation.

In Figure 5(c), the HH polarization of the paddy-I class has a lower backscatter coefficient and more repeated patterns than the paddy-II class. This backscatter coefficient pattern was similar to the paddy field pattern presented in the study from Zhang et al. (2009). The dynamic pattern of the backscatter coefficient from the paddy-I class was influenced by the moisture conditions, which changed during the paddy growing stages. As can be seen in Figure 5(c), the HH polarization of paddy-I class shows two graphs involving opposite temporal patterns. The first pattern consists of the paddy-I class from the acquisitions from January 30 (paddy I_0130) and July 3 (paddy I_0703), 2015. The second pattern concerns acquisitions from May 17 (paddy I_0517) and September 11 (paddy I_0911), 2015. However, all of the backscatter coefficients from the PALSAR-2 acquisition dates were low, with a value below $-15 \mathrm{~dB}$. Thus, the sample points were selected in the same stage of the paddy fields. Paddy I_0130 in Figure 5(c) represents the repetition of paddy cultivation in this study area.

The backscatter coefficient of paddy I_0517 and paddy I_0703 also increased from the backscatter coefficient in the acquisition date. Thus, the backscatter coefficient of $\mathrm{HH}$ polarization from the paddy-I class revealed the paddy fields' characteristics. In contrast to the paddy-I class, the HH polarization backscatter coefficient of the paddy-II class, as can be seen in Figure 5(c), showed an inconsistent temporal change and a high backscatter coefficient. The high backscatter coefficient is related to low moisture conditions or a rough surface, such as that in the dry condition area. In Figure 5(d), the HV polarization backscatter coefficient value of the paddy II_0130, paddy II_0517, paddy II_0703 and paddy II_0911 classes were around $-22 \mathrm{~dB}$ to $-16 \mathrm{~dB}$, that is, the same range as the upland fields class. This result was expected because the paddy-II class fields became upland fields when there was minimum water availability. 


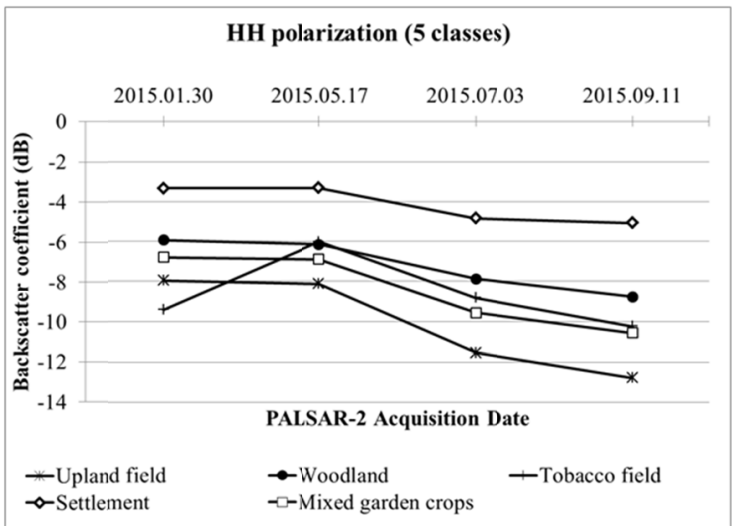

(a)

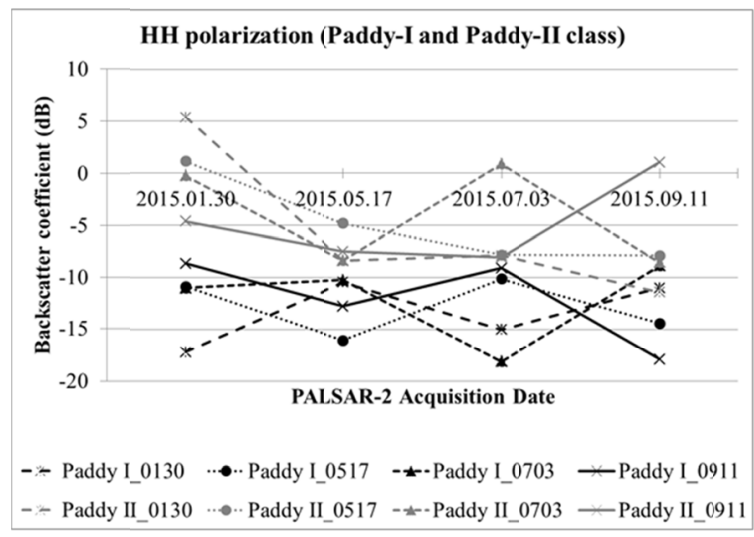

(c)

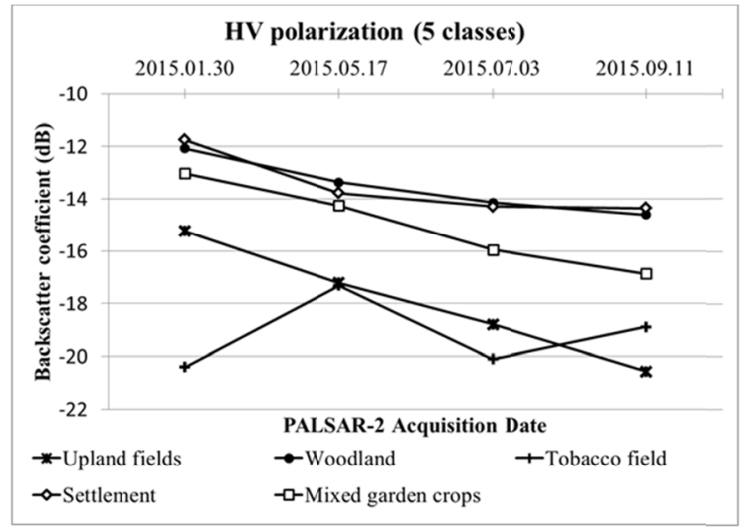

(b)

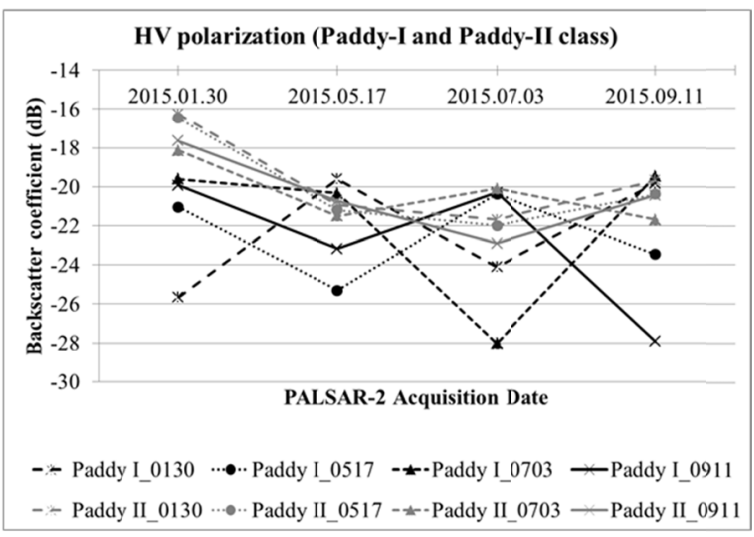

(d)

Figure 5. Averages of training points based on HH and HV polarization from each PALSAR-2 data: (a) and (b) for woodland, settlement, upland fields, tobacco fields, mixed-garden-crops classes; (c) and (d) for paddy-1 and paddy-II classes

\subsubsection{Classification Result Analysis}

Table 4 shows the overall accuracy and kappa coefficient values obtained from the classification process. In general, the classification result based on a single PALSAR-2 acquisition date was lower compared to the classification result for multi-temporal combinations. The 0911_A gave the highest accuracy amongst other single acquisition data sets, with an overall accuracy of $71.35 \%$ and a kappa coefficient of 0.66 . The classification result of 0911 is higher than other single date acquisition data because the dates of acquisition for the Pleiades and PALSAR-2 data taken on September 9, 2015, involve a short time gap and affect the sample points, which are based on visual interpretations of Pleiades data. In this study, PALSAR-2 data taken on May 17, 2015, are the only full polarization data.

The full polarization of PALSAR-2 data (0517_C) showed higher accuracy than the 0517_A classification, which consists of two polarizations, $\mathrm{HH}$ and $\mathrm{HV}$. The additional polarization of $\mathrm{HV}-\mathrm{HH}$ decreases the classification accuracy for 0130_B, 0517_B, 0703_B and 0911 B, as can be seen in Table 4. However, the addition of the HV-HH polarization causes an increase in the classification result of the full polarization data (0517_D). In Table 4, the classification of multi-temporal combinations shows a high level of accuracy. Temp_comb_1 obtained the highest accuracy with an overall accuracy of $85.02 \%$ and a kappa coefficient value of 0.824 . The additional band in temp_comb_2 and temp_comb_4 was not able to improve the accuracy. Therefore, higher classification accuracy can be achieved by using the multi-temporal combination of $\mathrm{HH}$ and HV polarizations.

Figure 6 shows producer accuracy and user accuracy in all classes for the temp_comb_1, 0130_A, 0517_A and 0911_A classification results. These classification results were chosen in order to compare the accuracy of all classes. According to Figure 6, the paddy-I and paddy-II classes displayed higher producer and user accuracy compared to other classes. 
Table 4. The overall accuracy and kappa coefficient of classification result

\begin{tabular}{llll}
\hline Combination name & Number of bands & Overall accuracy (\%) & Kappa coefficient \\
\hline 0130_A & 2 & 64.37 & 0.582 \\
0130_B & 3 & 63.91 & 0.577 \\
0517_A & 2 & 65.63 & 0.596 \\
0517_B & 3 & 62.99 & 0.567 \\
0517_C & 4 & 66.07 & 0.603 \\
0517_D & 5 & 67.4 & 0.619 \\
0703_A & 2 & 66.21 & 0.603 \\
0703_B & 3 & 64.41 & 0.585 \\
0911_A & 2 & 71.35 & 0.66 \\
0911_B & 3 & 70.98 & 0.655 \\
Temp_comb_1 & 8 & 85.02 & 0.824 \\
Temp_comb_2 & 12 & 76.4 & 0.724 \\
Temp_comb_3 & 10 & 80.6 & 0.775 \\
Temp_comb_4 & 14 & 73.03 & 0.685 \\
\hline
\end{tabular}

In the single date acquisition, as can be seen in Figure 6, the producer and user accuracy of paddy-I and paddy-II classes were typically above $90 \%$, with some obtaining $100 \%$ accuracy. These results confirmed that the selection based on the RGB composite of PALSAR-2 data is effective in increasing paddy field accuracy. However, the temporal combination of dual polarizations could increase producer or user accuracy in all classes, except the paddy-I and paddy-II classes. The sample points for multi-temporal classification were randomly selected from the sample points for single acquisition date classification. Thus, the producer and user accuracy of multi-temporal classification was lower than the single date classification result. In contrast with the paddy-I and paddy-II classes, the multi-temporal backscatter could have increased the probability of separating woodland, settlements, upland fields, tobacco fields and mixed garden crops classes.

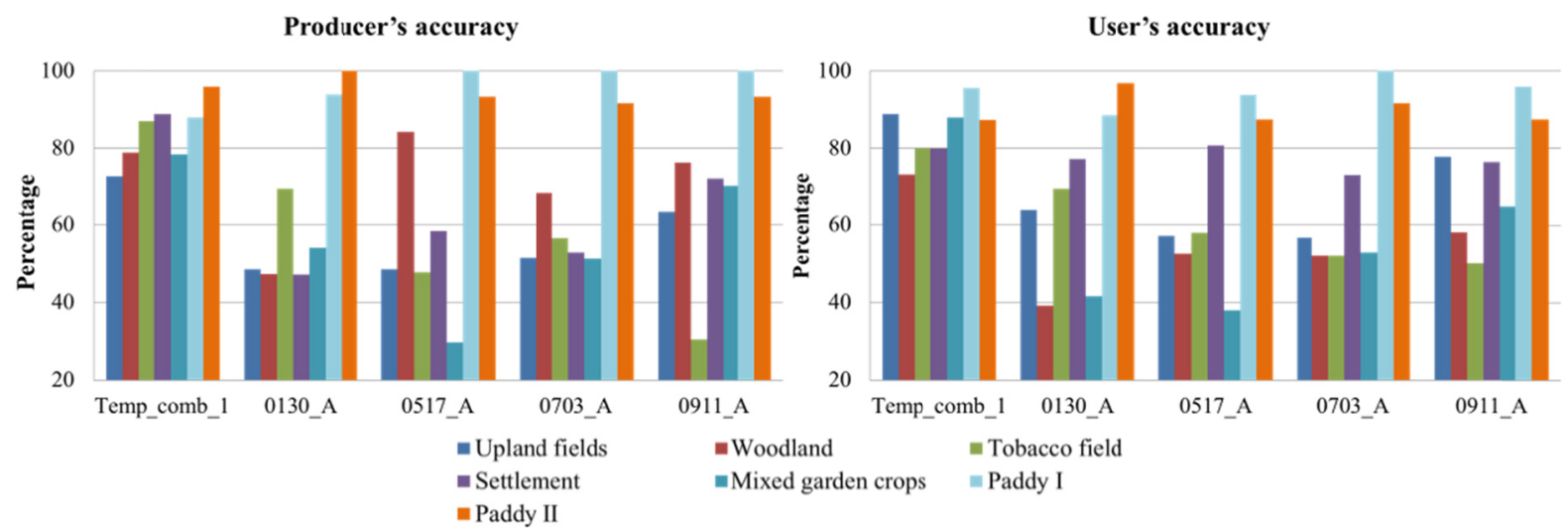

Figure 6. Producer's accuracy and user's accuracy of temp_comb_1, 0130_A, 0517_A and 0911_A classification result

Figure 7 shows the agriculture cropland classification results by using single date acquisition data (0130_A, 0517_A, 0703_A and 0911_A) and the multi-temporal combination (temp_comb_1). These classification results were chosen as the most representative comparison between single acquisition and multi-temporal classification results. The southern part was mostly classified as tobacco fields, as can be seen in Figure 7(a), and upland fields, as can be seen in Figures 7(b), 7(c), and 7(d). The settlement areas were misclassified as woodland or mixed garden crops. Therefore, producer and user accuracy for these classes was very low. The paddy-II class was used for classifying the area with cropping patterns of paddy fields in the rainy season and upland fields in the dry season. 


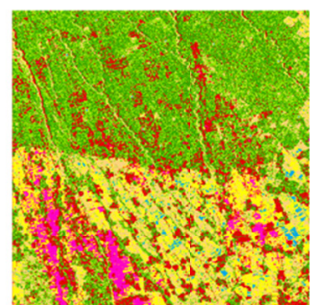

(a) $0130 \_\mathrm{A}$

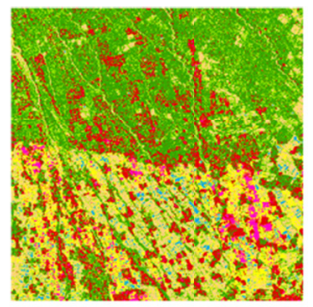

(c) $0703 \_\mathrm{A}$

Legend

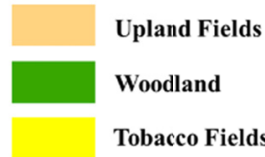

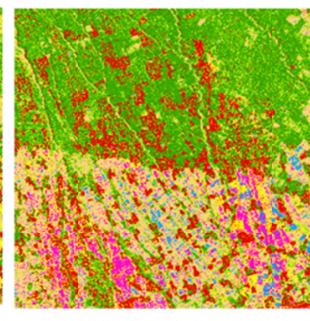

(b) 0517_A

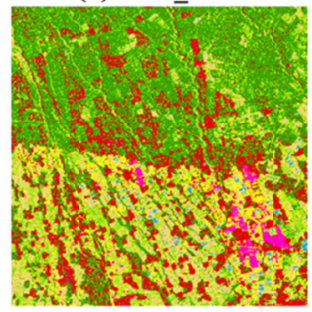

(d) 0911_A

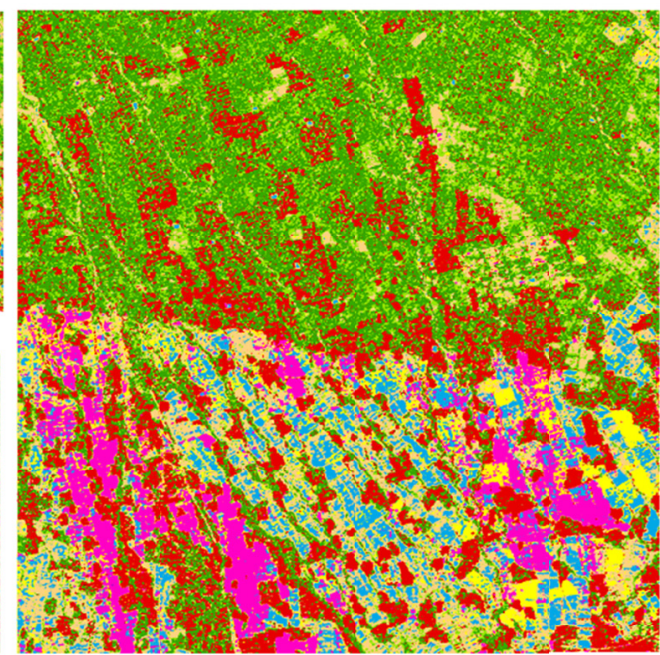

(e) Temp_comb_1

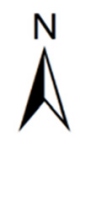

Figure 7. The classification result of (a) 0130_A, (b) 0517_A, (c) 0703_A, (d) 0911_A, and (e) temp_comb_1

In Figure 7(a), the area was classified as paddy-II, spreading out in the eastern part, while decreasing in the next acquisition time period (Figures 7(c)-7(d)). The paddy-I class was identified in smaller areas, compared to the paddy-II class, because the planting time for paddy fields was not coordinated, as it was decided by each farmer. However, by combining the multi-temporal dual polarization data (Figure 7(e)), the paddy-I and paddy-II areas became larger and easier to identify, even though the producer and user accuracies decreased. The coverage upland fields and mixed garden crops also decreased, which corresponds to higher accuracy. This result is similar to that reported in a study revealing that temporal SAR data are useful for classifying paddy fields (Y. Zhang, Wang, \& Q. Zhang, 2011). Therefore, the backscatter coefficient was found to be useful for separating the cropping patterns of paddy fields. Moreover, the highly accurate classification of complex agricultural croplands could be achieved by using a multi-temporal combination of dual polarization PALSAR-2 data.

\section{Conclusion}

This study shows the potential of PALSAR-2 multi-temporal data in examining complex agricultural croplands. In this study, the RGB composite of $\mathrm{HH}, \mathrm{HV}$ and $\mathrm{HV}-\mathrm{HH}$ and multi-temporal PALSAR-2 data were used and found to be very useful when identifying and classifying the particulars of complex agricultural croplands. The RGB composite of $\mathrm{HH}, \mathrm{HV}$ and $\mathrm{HV}-\mathrm{HH}$ supported the selection of sample points needed to separate two types of paddy field: the all-year paddy (paddy-I) and paddy upland field (paddy-II) cropping patterns, which are often found in this study area. By using this RGB composite, producer accuracy and user accuracy for paddy-I and paddy-II were very high compared to other land use classes. This study also achieved an overall accuracy of $85.02 \%$ and a kappa coefficient of 0.824 by using the multi-temporal combination of $\mathrm{HH}$ and $\mathrm{HV}$ polarization from four temporal data taken between January and September 2015. This multi-temporal combination was effective for classifying the agricultural croplands, which could increase overall accuracy by about $10 \%$, compared to the average of single date acquisition classification results. Moreover, these temporal combination data increased the producer and user accuracy of other land use classes, such as woodland, upland fields, tobacco fields, settlements and mixed garden crops up to 70\%. This study successfully demonstrated PALSAR-2's ability to identify and classify complex agricultural croplands.

\section{References}

Agus, F., \& Manikmas, M. O. A. (2003). Environmental roles of agriculture in Indonesia. Presented at the 25th Conference of the International Association of Agricultural Economists, Durban, South Africa. Retrieved from ftp://193.43.36.92/es/esa/roa/pdf/2_Environment/Environment_IndonesiaNA.pdf 
Cazals, C., Rapinel, S., Frison, P.-L., Bonis, A., Mercier, G., Mallet, C., ... Rudant, J.-P. (2016). Mapping and characterization of hydrological dynamics in a coastal marsh using high temporal tesolution Sentinel-1A images. Remote Sensing, 8(7), 570. https://doi.org/10.3390/rs8070570

Congalton, R. G. (1991). A review of assessing the accuracy of classification of remotely sensed data. Remote Sensing of Environment, 37(1), 35-46. https://doi.org/10.1016/0034-4257(91)90048-B

Helmer, E. H., \& Ruefenahct, B. (2005). Cloud-free satellite image mosaics with regression trees and histogram matching. Photogrammetric Engineering and Remote Sensing, 71(9), 1079-1089. https://doi.org/10.14358/ PERS.71.9.1079

Inoue, Y., Sakaiya, E., \& Wang, C. (2014). Potential of X-Band images from high-resolution satellite SAR sensors to assess growth and yield in paddy rice. Remote Sensing, 6(17), 5995-6019. https://doi.org/ $10.3390 /$ rs6075995

JAXA (Japan Aerospace Exploration Agency). (2014). ALOS-2/PALSAR-2 Level 1.1/1.5/2.1/3.1 CEOS SAR Product Format Description. Retrieved from http:/www.eorc.jaxa.jp/ALOS-2/en/doc/fdata/PALSAR-2 xx_Format_CEOS_E_r.pdf

JAXA (Japan Aerospace Exploration Agency). (2017). Calibration result of ALOS-2/PALSAR-2 JAXA standard products. Retrieved from http://www.eorc.jaxa.jp/ALOS-2/en/calval/calval_index.htm

Kankaku, Y., Suzuki, S., \& Osawa, Y. (2013). ALOS-2 mission and development status. Geoscience \& Remote Sensing Symposium, 2014 (pp. 2396-2399). Melbourne, Australia: IEEE. https://doi.org/10.1109/IGARSS. 2013.6723302

Lavigne, F., Coster, B. D., Juvin, N., Flohic, F. M., Gaillard, J.-C., Texier, P., ... Sartohadi, J. (2008). People's behavior in the face of volcanic hazards: Perspectives from Javanese communities, Indonesia. Journal of Volcanology and Geothermal Research, 172, 273-287. https://doi.org/10.1016/j.jvolgeores.2007.12.013

Mas, J. F., Vega, A. P., Ghilardi, A., Martinez, S., Carrillo, J. O. L., \& Vega, E. (2014). A suite of tools for assessing thematic map accuracy. Geography Journal, 2014(10), 1-10. https://doi.org/10.1155/2014/372349

Mei, E. T. W., Lavigne, F., Picquout, A., Bélizal, E. D., Brunstein, D., Grancher, D., ... Vidal, C. (2013). Lessons learned from the 2010 evacuations at Merapi volcano. Journal of Volcanology and Geothermal Research, 261, 348-365. https://doi.org/10.1016/j.jvolgeores.2013.03.010

Mishra, P., Singh, D., \& Yamaguchi, Y. (2011). Land cover classification of Palsar images by knowledge based decision tree classifier and supervised classifiers based on SAR observables. Progress in Electromagnetics Research B, 30, 47-70. https://doi.org/47-70. 10.2528/PIERB11011405

Nelson, A., Setiyono, T., Rala, A., Quicho, E., Raviz, J., Abonete, P., ... Ninh, N. (2014). Towards an operational SAR-based rice monitoring system in ASIA: Examples from 13 demonstration sites across Asia in the RIICE project. Remote Sensing, 6(11), 10773-10812. https://doi.org/10.3390/rs61110773

Nofrita, S., \& Krol, B. G. C. M. B. (2014). The Livelihood Analysis in Merapi Prone Area after 2010 Eruption. Indonesian Journal of Geography, 46(2), 195-207. https://doi.org/10.22146/ijg.5790

Rosenqvist, A., Shimada, M., Suzuki, S., Ohgushi, F., Tadono, T., Watanabe, M., ... Aoki, E. (2014). Operational performance of the ALOS global systematic acquisition strategy and observation plans for ALOS-2 PALSAR-2. Remote Sensing of Environment, 155, 3-12. https://doi.org/10.1016/j.rse.2014.04.011

Tian, X., Chen, E., Li, Z., Su, Z.B., Ling, F., Bai, L., \& Wang, F. (2010). Comparison of crop classification capabilities of spaceborne multi-parameter SAR data. Geoscience and Remote Sensing Symposium, 2010 (pp. 359-362). Honolulu, HI, USA: IEEE. https://doi.org/359-362.10.1109/IGARSS.2010.5651326

Torbick, N., Chowdhury, D., Salas, W., \& Qi, J. (2017). Monitoring rice agriculture across Myanmar using time series sentinel-1 assisted by Landsat-8 and PALSAR-2. Remote Sensing, 9(2), 119. https://doi.org/ $10.3390 / \mathrm{rs} 9020119$

USGS (U.S. Geological Survey). (2014). Landsat 8 data users handbook. USGS Earth Resources Observation and Science, Sioux Falls, South Dakota, USA. Retrieved from https://landsat.usgs.gov/sites/default/ files/documents/Landsat8DataUsersHandbook.pdf

USGS (U.S. Geological Survey). (2017). Product guide Landsat surface reflectance-derived spectral indices. USGS Earth Resources Observation and Science, Sioux Falls, South Dakota, USA. Retrieved from https://landsat.usgs.gov/sites/default/files/documents/si_product_guide.pdf 
Yusoff, N. M., Muharam, F. M., Takeuchi, W., Darmawan, S., \& Razak, M. H. A. (2016). Phenology and classification of abandoned land based on ALOS-1 and 2 PALSAR multi-temporal measurements. International Journal of Digital Earth, 10(2), 155-174. https://doi.org/10.1080/17538947.2016.1216615

Zhang, Y., Wang, C., \& Zhang, Q. (2011). Identifying paddy fields with dual-polarization ALOS/PALSAR data. Canadian Journal of Remote Sensing, 37(1), 103-111. https://doi.org/10.5589/m11-016

Zhang, Y., Wang, C., Wu, J., Qi, J., \& Salas, W. A. (2009). Mapping paddy rice with multitemporal ALOS/PALSAR imagery in southeast China. International Journal of Remote Sensing, 30(23), 6301-6315. https://doi.org/10.1080/01431160902842391

\section{Copyrights}

Copyright for this article is retained by the author(s), with first publication rights granted to the journal.

This is an open-access article distributed under the terms and conditions of the Creative Commons Attribution license (http://creativecommons.org/licenses/by/4.0/). 